recipients of Nobel prizes for physics, chemistry and medicine (more than one quarter) have passed to Germans. Herr Hitler has decreed the creation of three German National Prizes of 100,000 marks $(£ 8,300)$ each, to be awarded annually to Germans distinguished in art and science.

\section{Gold Medal of the International Faculty of Sciences}

AT the dinner following the annual conference of the International Faculty of Sciences applied to Human Progress, held in London on January 30, the Faculty's Gold Medal was presented to Mr. John Logie Baird, inventor of the Televisor, and managing director of Baird Television, Ltd. The chairman, Dr. Joseph S. Bridges, said the presentation was made in recognition of $\mathrm{Mr}$. Baird's outstanding contributions to the science of television. In acknowledging the presentation, Mr. Baird indicated the progress that had been made since he first, in 1925, secured a television image with distinct definition. While the high cost of the apparatus at present is a drawback to its wide use among amateurs, he looked forward to a substantial reduction in the near future. Great Britain, he said, definitely leads in the science of television and is the only country in the world which has a television service. Among other speakers, Dr. L. E. C. Hughes commented on the necessity of scientific workers in all branches co-operating more closely to ensure that the achievements are properly applied to the requirements of human progress, and indicated the value of the International Faculty of Sciences in bringing into close touch such workers in all the countries of the world. Prof. B. W. Holman, replying on behalf of "The World's Scientific Workers", stressed the necessity for the social sciences being developed to keep pace with other sciences, so that the achievements of the research workers could be applied in accordance with the objectives of the Faculty, namely, human progress.

\section{Aboriginal Tribes of the Malay Peninsula}

WHILE of the aboriginal tribes of the Malay Peninsula the Sakai, the Semang and the Jakun, though by no means well known, have been the subject of careful investigation by a number of observers, the Temiar, a hill people of Perak, are virtually untouched in an anthropological sense. Yet they number nearly one half of the aboriginal population of 25,000. They have, however, been made the subject of a considerable study by Mr. H. D. Noone of the Perak State Museum, who has given some years to the investigation of their culture, their ethnic affinities, and their language, which is said to belong to the Austro-Asiatic group, and to show IndoChinese affinities. A preliminary outline of $\mathrm{Mr}$. Noone's results in The Observer of January 24 is cabled from Singapore, where a number of the tribe are staying at present for the purpose of a record of their speech. It is there stated that Mr. Noone finds that the Temiar show traces of negritic influence and also an Australoid type, akin to the Vedda, but that, essentially a hill tribe, they link up with the hill stocks of Sumatra and other parts of south-east
Asia. They are lighter skinned than the Sakai and belong to a higher order of intelligence and culture. They build communal long-houses instead of the rude shelters of the Sakai, use the bow, and hunt with the blow-pipe. Their religion is animistic. For driving out the spirits of disease, they make use of the religious dance, in which the medicine man is an important figure. These dances are performed in the event of an epidemic, the dancers becoming 'possessed' by a tiger spirit. Eventually they fall into a state of trance, which sometimes ends in complete rigidity.

\section{Tracks for Cyclists}

THe recent Ministry of Transport accident inquiry proves that, notwithstanding the increase in the number of motor-cars, the casualties among motorists are decreasing. On the other hand, casualties to cyclists are increasing at an even greater rate than we might expect from the growth of the cycling habit. According to a paper read at the National Safety Congress, fatal accidents to pedal cyclists during the seven years 1928-34 had increased no less than 122 per cent. In Roads and Road Construction for January 1 , it is suggested that the best way to check increase of these accidents would be to copy some of our Continental neighbours and increase largely the number of special cycle tracks available. In Germany there are already about 1,100 miles of track, about two thirds of which is State maintained. According to a recent statement, the decrease which has occurred in recent years in cycling fatalities in Germany can be attributed directly to the making of these tracks. The German authorities are aiming at the provision of no less than 24,000 miles of track. The opposition that cyclists' touring clubs make to special tracks seems to arise from a fear lest these tracks be made not wide enough, so that they will have to travel at the most two abreast, instead of as at present three or four or even more abreast. In the interest of the general safety, it is probable that the privilege of riding three or more abreast will soon be curtailed by law. In many places cycle tracks, like public footpaths, could be built without fences, and probably a large mileage of existing 'green roads' could be utilized. If a number of special tracks were constructed every year, the annual cost need not be large. They would add safety, health and enjoyment to the weekly tours of many cyclists who at present have to pass through main roads crowded by rapidly moving vehicles and sometimes in an atmosphero full of noxious vapours.

\section{Road Lighting in the United States}

IN World Power of November some interesting statistics are given, relating to road accidents, which illustrate the responsibility of bad or non-existent lighting for road deaths and injuries. On the Mount Vernon Highway, near Washington, there were $2 \cdot 87$ accidents per million vehicles per mile, between July 1 and December 1, 1932. When lighting was suspended during the depression, the number of accidents increased to $7 \cdot 02$ over the same period per million vehicles per mile-an increase of 250 per cent. 
In New Jersey at present, the night-time acciclent rates on three unlighted main roads carrying dense traffic are 270 per cent more than the day-time rates. Another striking figure is that more than half the 36,400 people killed by motor-cars in 1935 were injured during the hours of darkness, although the braffic volume was certainly not more than one third that during the day-time. It is concluded that it is not surprising that American engineers are alarmed when they see that New York State, for example, makes an annual expenditure of about twenty-two million dollars in getting rid of railway, street and highway crossings, and yet does little towards the illumination of roads at night. The total number of preventable accidents in 1934 due to railway crossings was 151 .

\section{Merseyside Fauna and Flora}

The Liverpool Naturalists' Field Club has recently issued volumes of Proceedings covering its activities for 1934 and 1935. This brings its number of annual Proceedings since its inception in 1860 to seventy-five, a noteworthy accomplishment, for they provide a valuable reference on the changing fauna and flora of the industrial north-west of England. The two latest volumes consist largely of the Ornithological Section report by Eric Hardy, who has built up within the Society the largest organized bird study group in the area. This includes bird-census counts over special areas, organized surveys of bird-calls at dawn and dusk, and statistics of migration and birdringing, nesting and rookery counts, etc. The Ornithological Section, states the Committee Report, is now organized independently of, but connected with, the general Field Club. The Proceedings also include Mr. W. A. Makinson's presidential addresses for the two years : "The Joys of a Nature Lover" and "Trees and their Service to Man". Reference is made to the discovery, in the Field Club library, of proof that the Society's first president and founder, the Rev. H. H. Higgins, visited the convent at Sinai and examined the famous "Codex Sinaiticus" previous to the examination by the collector Tischendorf. Having traced the journals of this Sinai visit, it is hoped to publish them.

\section{The Scripps Institution of Oceanography}

The August issue of the Collecting Net (11, No. 5) contains an article entitled "Biological Research at the Scripps Institution of Oceanography" by Dr. Claude E. ZoBell. It is announced that Dr. T. Wayland Vaughan is retiring from the University of California, his successor being Dr. Harald U. Sverdrup. During Dr. Vaughan's administration, the Scripps Institute of Oceanography has expanded enormously, and since his appointment as director in 1924 he has gradually developed an extensive research programme in biological oceanography with workers in all subjects connected with it. Among the many great improvements an important one is the growth of the library, which now contains more than 14,600 volumes, 1,100 charts and 30,000 pamphlets. Dr. Vaughan has contributed to the Institution his own personal collection of 1,800 volumes and 6,000 reprints of relevant literature besides numerous periodicals.

\section{Physics Research at Osaka University}

VoL. 3 of the "Collected Papers in Physics" from Osaka University consists of thirteen copies of papers which have appeared in the Report of Radio Research in Japan, the Proceedings of the Physico-Mathematical Society of Japan, the Japanese Journal of Physics and the Proceedings of the Institute of Radio Engineers of the United States, between June 1935 and March 1936. They cover subjects such as atomic bombardment, short-wave production, modulation of oscillators, polar molecules, electron diffraction, neutrons and protons and dynatrons. The volume extends to about 125 pages, and is produced by wiring together the separate copies of the papers, with a title page and table of contents, the size of the page being $19 \mathrm{~cm}$. by $26 \mathrm{~cm}$. The original covers of the papers are retained. This inexpensive method of issuing collected papers from periodicals with pages of the same size seems worthy of extension.

\section{Misunderstanding and Misprint}

A CoRrespondent has sent us a copy of a programme for 1936-37 of a science society of a university, which contains two amusing misprints. The title of a paper to be contributed by a member of the zoological department of the university was sent in as "Life History of the Ling Cod". The secretary appears not to have recognized "ling" as a food fish of the cod family, so he altered the word to "living". The printers put the finishing touch upon the title by changing the last word also, so that the title appears as "Life History of the Living God", which must surely represent the most ambitious subject of a paper by a zoologist ever announced.

\section{The Influenza Epidemic}

The Ministry of Health reports that during the week ending January 16 the number of deaths ascribed to influenza in the 122 great towns of England and Wales was 1,100 , as compared with 768 in the previous week. The number of notifications of pneumonia in England and Wales was 2,823 as against 2,338 in the previous week. A considerable increase of influenzal cases has occurred in most of the naval and military commands; but the epidemic appears to be declining in certain parts of the south. The age distribution of deaths is somewhat reassuring, as it is not the type usually met with in severe epidemics. According to Science Service bulletins, a wave of influenza is passing over the United States.

\section{Parkes Memorial Prize}

Major E. F. W. MackenzIE, R.A.M.C., has been awarded the Parkes Memorial Prize for 1936 for his investigations into the ammonia-chlorine process of water purification in the field, coupled with research carried out by him in connexion with food supplies in India. The Parkes Memorial Prize is awarded 